\section{SCIENCE AND TECHNOLOGY IN CHINA'S FAR SOUTH-EAST}

\author{
By Dr. JOSEPH NEEDHAM, F.R.S. \\ British Scientific Mission in China
}

$\mathrm{T}$ HE two provinces covered in this article are those of Kuangtung and Fukien. Both differ widely in their dialects from all other parts of China and from each other, and during the War they had a different fate. In the campaign of 1944, the Japanese driving south along the Hankow-Canton railway linked up with the Japanese coming up from Canton, ospturing Kuangtung's temporary provincial capital, Kukong, and destroying the scientific institutions in its neighbourhood. Fukien, on the other hand, ringed round as it is on the landward side by mountains and forests, has suffered only intermittent Japanese occupation of its main ports, Fuchow and Hsiamên (Amoy). It remains a sort of Valley of Avalon, isolated, with its two excellent universities, from the ravages of war in the plains of Chiangsi and Kuangtung to the west.

Kukong, as it appeared to a visitor in 1944, was a particularly pleasant city, built on sandy soil at the junction of the Peichiang and one of its main tributaries, with flowery gardens, and streets arcaded in southern style against the sun. To the north, some four hours by train, up a noble defile in the mountains followed by river and railway, at Pingshek, was the Chungshan (Sun Yat-Sen) University, with outlying colleges, especially that of agriculture, at Liyuanbao; and the Lingnan University College of Agriculture at Pingshek itself. Nearer towards Kukong, at a small town called Lochang, was the Chungshan Medical College. Nearer still, at a halt in moorland country called Hsienrjêngmiao ("Fairy Temple") were the two Universities of Lingnan and Tungwu. Finally, in Kukong itself was the Lingnan Medical College.

The largest of these organisations, Chungshan University (acting president, Chin Tsêng-Têng), had had a particularly melancholy history of evacuation. Before the original fall of Canton, it had made its way to far-off Yunnan, but after becoming established there, was recalled by the Kuangtung Provincial Government. It was estimated that one third of the equipment was lost on the outward journey, and another third on the way back. Though still including some eminent scholars, such as Dr. Chu Chien-Tze (historian of Asiatic-European culture contact), Dr. Yang Chêng-Chih (editor of the Journal of Chinese Folklore), Dr. Wu Kang (philosophy), Dr. Wang Ya-Nan (economic history), and Dr. Shêng Cheng (pupil of Bataillon at Montpellier and friend of Patrick Geddes) for whose autobiography Paul Valéry wrote a preface-Chungshan was but a shadow of its former self.

On the scientific side it is noteworthy that among all Chinese universities, Chungshan alone maintained an astronomical observatory. Under the remarkable woman director Dr. Chou Yi-Hsin, teaching work with about a dozen students was proceeding with a 6 -in. equatorial telescope. A transit instrument used as zenith telescope for determination of latitude and time from star positions was set up and in use.

In the biological laboratories Dr. Chang Tso-Rjêng (a pupil of Guilliermond's), whose inspiring influence on the students was obvious, was working on the nuclear cytology of root-hairs under the influence of colchicine. Though good microscopes were available, many substitutions, such as that of gasoline locally produced by cracking camphor oil, for xylol, had to be made. Systematic ornithology was flourishing under Rjên Kuo-Rjung from the Paris Museum, and systematic botany under Yung Chi-Tung. Biological work on a much larger scale was in progress at the Agricultural College some $40 \mathrm{~km}$. away at Liyuanbao. Of outstanding interest was the very active work of Dr. Chao Shan-Huan and his collaborators (who have been, through the British Scientific Mission, in touch with Dr. Tattersfield and others) on naturally occurring insecticides. The chicken-blood vine, Millettia pachycarpa, had proved as good as derris against a wide variety of insects, such as biting lice, plant bugs, aphids, leaf beetles, house flies, lice and bedbugs. Similar good results had been obtained with the thundergod vine, Tripterygium exesum, and with the yam bean, Pachyrrhyzus eresus. The whole of this work, which included also the mass production of arsenical and copper sprays, etc., from local minerals, was a model of energetic and resourceful action under most difficult conditions. Another strong line of this College was soil science, under the veteran dean, Dr. Têng Chih-Yi, who had organised an excellent provincial soil survey and a soils museum. Notable also was the work of Wên Wên-Kuang (plant growth-hormones), Fêng Tze-Ching (sex hormones in domestic animals), Dr. and Mrs. Pu Chih-Long (pathology of the silkworm), Dr. Chiang Ying (systematic botany and wood anatomy), and Lo Tong-Chien (forestry), who had started plantations of the lightest of known woods, Paulownia fortunei, for the Chinese Air Force. All in all, this agricultural college was perhaps the largest and best, both for research and teaching, which I have seen in my wanderings in China.

Chungshan University Medical College (dean, Li Yu-Sêng), at Lochang, with its teaching hospital in very modernistic style (though constructed only of local materials, wood, bamboo, brick and plaster), showed markedly the influence of the German training of most of its staff, in the order and cleanliness typical of old-fashioned German culture. Outstanding here was the pathologist Dr. Liang Po-Chiang, who had a good deal of research going on, for example, on schistosomiasis, on curious miliary abscesses of the spleen (common in North Kuangtung) probably caused by Spirochoeta recurrens, on congenital intestinal diverticula, on fœtal chondrodystrophy, etc. This medical school was designed for 150 students but had actually 300. Dr. Yang Chien, in anatomy, completely lacking preservatives, was back in the sixteenth century with Vesalius, and had to get dissections finished in one or two days.

Lingnan University occupied one of the most beautiful temporary campuses in China, some distance from the railway, in a magnificent grove of camphor trees, with wooden buildings with porches and verandahs of pleasant design. The parasitologist Dr. Chen Hsing-Tao was head of the faculty of science here, there being very little physics or chemistry. The medical college was headed by Dr. Ling Shu-Mo, a former collaborator of the Eggletons at Edinburgh, who had worked with them on phosphagen and carnosine. Since returning to China he had had little opportunity for research.

To go to Fukien Province from Kukong, one must travel across the Province of Chiangsi, with its very good roads, passing through the large town of 
Ganhsien, formerly the headquarters of the thriving south-eastern Chinese Industrial Co-operative Federation. At the time of my visit, many co-operatives were still working, and the machine-shop and boatbuilding yard were both visited. Eventually, after passing through tumbled and forested mountain country, one crosses the border and reaches the small town of Changting, the war-time headquarters of Amoy University. Parallel to it, in the north of the province, on the only other road leading to and from Fukien from the interior, lies Shaowu, the war-time location of Fuchow University. Though the former is of governmental and the latter of missionary origin, both are of high quality and compare very favourably with the four great universities of the far west (see Nature, 153, 238; 1944 and references there to earlier articles). They are also in a happier position than most Chinese universities, in that their trek of only a few hundred kilometres was comparatively short, and the volume of books and equipment, brought directly up the rivers, is considerably larger than that of the universities which had to travel for perhaps two thousand kilometres or more.

At the time of my visit to Changting, President Sah Bên-Tong, a well-known electrical engineer, had just left for the United States, and my old friend from Roscoff and Paris days, Wang Teh-Yao (pupil of Wintrebert's), was acting for him. The University Library has a beautiful building, the guildhouse or hostel and temple combined of the Chiangsi merchants who formerly came to Changting to trade with the merchants of Fukien. In the scientific faculties there is a good deal of activity. Thus Dr. Chen Tze-Ying (a pupil of T. H. Morgan's), who did formerly a classical piece of work on imaginal buds, now keeps the best Drosophila stocks in China (using the sweet potato instead of the banana as food), though most of his war-time activity has been the making of agar from the seaweed Geladium cartilagenium of the Fukien coast (mostly quite clear of the enemy), and of anti-goitre preparations from other seaweeds, especially Eklonia. The promising young biologist Liao Hsiang-Hua works on isopod parasites, especially a queer one named Icthyoxenus chengi, which forms an enormous pouch within the belly of the loach Crossostoma stigmata. In physics, Dr. Chou Chang-Ning (a Cavendish man), though very isolated, is still doing theoretical work on cosmic rays. $\mathrm{He}$ had seen no new journals for four years, he had no electric current, no vacuum grease, in fact no means of using even the small amount of apparatus in stock. But by some method known only to himself, he was still keeping fairly cheerful. The geologist Chen Yün-Tun had exerted himself in making slide rules, logarithmic and other graph paper, for sale. This is an example of the initiative of Fukien people, just as photographic paper was being made at Yungan; but few of these products were getting out to the other provinces in the farther interior. The physical chemist Tsai ChiRjui had managed to do some very interesting work on the determination of mixtures of lower fatty acids up to valeric by the E.M.F. of hydrolysis of their cadmium salts, using a distribution coefficient method.

At Shaowu, in the north of the province, at Fuchow University, the picture was similar. Under President Ling Ching-Rjun, the library, augmented by Chinese books from many famous Fukien families, has become one of the best in all China. The biological laboratories are also unusually extensive, and Dr. Chêng TsoHsin, who heads the department, said that it had been a positive advantage to them to move into the country from Fuchow, as a different faunistic zone had been made available for study. There were very large collections of birds and reptiles, and a large marine collection. It was interesting to see specimens of the giant tree-toad Rhacophorus schlegelii which used to be worshipped by the Fulkien peasants. A recent popular exhibition arranged by the students had been crowded out by the townspeople. The able entomologists Chao Hsiu-Fu (dragon-flies) and $\mathrm{Ma}$ Chün-Chao (of the provincial entomological survey), and the parasitologist Tang Chung-Chang, a specialist on blood flukes, were hard at work. Dr. Ting Han-Po was making parabiosis and hybridization experiments with the interesting local species Pachytriton brevipes.

This University maintains a special Tea Research Laboratory (Chang Tien-Fu). It is very near the famous Wu-I (Bohea) Hills, where fine tea is grown. We brought away a number of tins of the universitymade tea, which has a high reputation. Other branches of agricultural science are also active, under a number of Cornell men, with large gardens and an experimental farm.

Though chemistry and physies are now practically confined to teaching here, the level which this formerly attained is attested in a remarkable way. Dr. Ling I, a Fuchow University graduate, who has never studied outside China, has been responsible for an industrial development of exceptional interest and great value for the Province. During the past few years, with the blockade entirely cutting off supplies of gasoline, the provincial buses and trucks have been running almost exclusively on a gasoline prepared from cracking the turpentine-like oil obtained by dry distillation of pinewood roots, which would otherwise be thrown away. The northern part of the province has a network of river communications which bring down the roots to several central distilleries. Unlike aliphatic vegetable oils such as tung oil, cracked so widely throughout China, the aromatic pinewood oil cracks with difficulty. The necessary aluminium catalyst is provided by balls of a local acid clay, like fuller's earth, which are suspended in wire cages above the oil in the cracking chambers. The octane number of the gasoline as finally used is quite high-about 75 . The main plant has an excellent lubricants and analytical laboratory in the buildings of a finely carved old temple. When it is remembered that the greater part of the apparatus is constructed out of old steel gasoline drums, bamboo piping, and derelict boilers from the Fuchow navy yard, some idea of the initiative and perseverance of Dr. Ling $I$ and his chief chemist Dr. Ni Sung-Mao can be gained. Fulfilling its purpose admirably within the province, this enterprise was one of the most inspiring examples of war-time improvisation $I$ have seen in China, and holds considerable possibilities for the use of by. products of the lumber industry even for peace-time.

There are many other ways in which Fukien is an interesting province from the scientific point of view. It is the only province in China to have a provincial Academy of Sciences. This is located at the temporary capital, Yungan, and has initiated work in agriculture, industrial chemistry, biology and soil conservation. At the time we were there it was suffering greatly from lack of apparatus and funds, but important botanical collections were being made by Dr. Ling Rjung, who has discovered many new species in the unexplored, hinterland of the province. The head of the Academy is Dr. Chou Chang-Yün, who also heads the very active provincial geological and soils survey 
Another notable figure at Yungan is Dr. Shih YenHan, head of the provincial meteorological survey, the best in China. The Yungan station is an elaborate one with an excellent library, and we were able to forward to Britain a complete set of the records and publications. Printing in Fukien is better than elsewhere in China, so that works such as Dr. Ma Ting-Ying's "Past Climate and Continental Drift" have been published by the Survey. The provincial agricultural college, too, was well-equipped and active under the leadership of Dr. Yen Chia-Hsien, and it was interesting to visit the power plant, producing $130 \mathrm{~kW}$. from an $11 \mathrm{~m}$. fall, with entirely Chinese-made piping, turbines, and dynamos. Mention should also be made of Huanan Women's College at another city, Nanping, where neat science teaching facilities were found; if Ginling College at Chengtu is China's Girton, this is its Newnham.

Unfortunately, it has been necessary to use the past tense in this article also. Having established a line of communications with these various institutions, I returned to the west, a few steps ahead of the Japanese, only to find that with the loss of Kuangsi, all contact with the scientific workers in Fukien was cut off, while the institutions in Kuangtung were before long disbanded and destroyed. After the examinations in the summer of last year, the students at Chungshan, Lingnan, and Tungwu Universities, and their agricultural and medical colleges, disbanded; and later the teaching and research staff also dispersed into the zones away from the roads and railways, taking with them in bits and pieces what equipment they could. It is said that the Chungshan Medical School has re-formed itself at Meihsien, in eastern Kuangtung, a district not occupied by the Japanese; but if so it is quite isolated. We have been able to welcome a few scientific men here mentioned, such as Liang Po-Chiang, Ling Shu-Mo, and Chêng Tso-Hsin, who managed to find their way to West China, but the majority have remained behind, and nothing is known of their activities. Thus the two Kuang Provinces have suffered the worst damage to science and technology during 1944, while Fukien is completely isolated. This is extremely regret. table, because some of the best scientific institutes in China were in the far south-east.

\section{NUTRITION IN JAPAN By Dr. GEOFFREY H. BOURNE}

TAPAN is a country of eighty million people and $\checkmark$ her pre-war empire (including Manchuria) embraced 105 million people. The problem of feeding such numbers has been considerable, and the diffculties which Japanese communications experienced as a result of Allied air and sea attack did not make this problem any simpler. It will perhaps be of interest at this stage, therefore, first to discuss Japanese diet and then to analyse the food situation in that country.

Generally speaking, the chief types of food now eaten in Japan include polished rice, with a certain amount of fish, beef, veal, pork and mutton and a few eggs, together with some Western vegetables and soya bean in various forms, particularly as soya bean curd. This last is made by soaking the beans in water, mashing them, straining the mass through cloth and solidifying it by the addition of magnesium chloride. Rice was first eaten in Japan in the unpolished condition; but as soon as the milling and polishing of rice was introduced the custom of eating the grain in this condition began to spread and rapidly extended to all classes of the population.

The diet of the Japanese cannot be described as good. Milk and butter, for example, play little part in it. Butter was probably introduced in Japan during the latter part of the eighteenth century and milk was introduced some time later by a Korean who brought it from Chosen. The first milk was used in medicine and was served only at great feasts, and butter was also served at feasts pounded up in rice cakes. Although both butter and milk were introduced early in Japan, neither entered into the lives of the common people.

In general, the Japanese diet can be described as predominantly carbohydrate in nature, which results, in effect, in an increased demand for vitamin $B_{1}$. At the same time, the vitamin $B_{1}$ content of the diet is reduced by polishing the rice, which is the predominant carbohydrate. Dr. E. C. Grey says (League of Nations publication, 1928) that the physical nature of rice is such that people are bound to use it in the polished condition. Rice must be consumed as a grain; it lacks gluten, the elastic constituent of wheat flour which enables it to be made into bread and macaroni. "The natural rice grain," says Dr. Grey, "is rough to the tongue and unpleasing to the palate, it is not so easily digested and has none of the pleasing appearance of the pure white grains of polished rice."

The Japanese diet is also deficient in fat. In 1928 the daily intake of this nutrient was only about 15-20 gm. a day, which is only about one quarter of the desirable intake. 85 per cent of the fat which was consumed was vegetable fat and therefore contained no fat-soluble vitamins. In 1925 the average daily calorie intake in Japan was approximately 2,732. This is the figure for food before it was prepared for the table. Allowing 10 per cent for wastage the figure comes to little more than 2,400 calories, which, considering that the main mass of the people are manual workers, was too low.

Protein was derived prineipally from fish and soya beans, and a very small quantity from beef and other meats in certain classes. Fish and other marine products are not entirely satisfactory as the sole sources of animal protein because of the variation in the seasons. When there is a good season, fish is so plentiful that it is used as manure; when a bad season arrives there is not enough fish to go round. Soya bean, which contains a high-quality protein, forms the most stable source of protein.

The foeding of Japanese children, particularly those of the working classes, has always been extremely poor. The lack of milk is one of the principal reasons for this. Even that which is available is produced under very unhygienic conditions, and the effects of drinking it are usually far from good. In fact, this unattractiveness of animal foods is possibly one of the reasons (apart from cost) why Japanese people eat very little of them; another reason is, of course, that few people know how to cook them. As a result of the deficiency of cow's milk, Japanese children tend to be breast-fed for a very long time. Attempts are made to use a substitute milk made from the soya bean. Infant feeding and hygiene does not appear to have improved very much in recent years, for the average mortality for the five-year period 1934-39 was still 115 per 1,000 live births, which is 